\title{
Successful endoscopic closure of spontaneous esophageal rupture (Boerhaave syndrome) $\square$
}

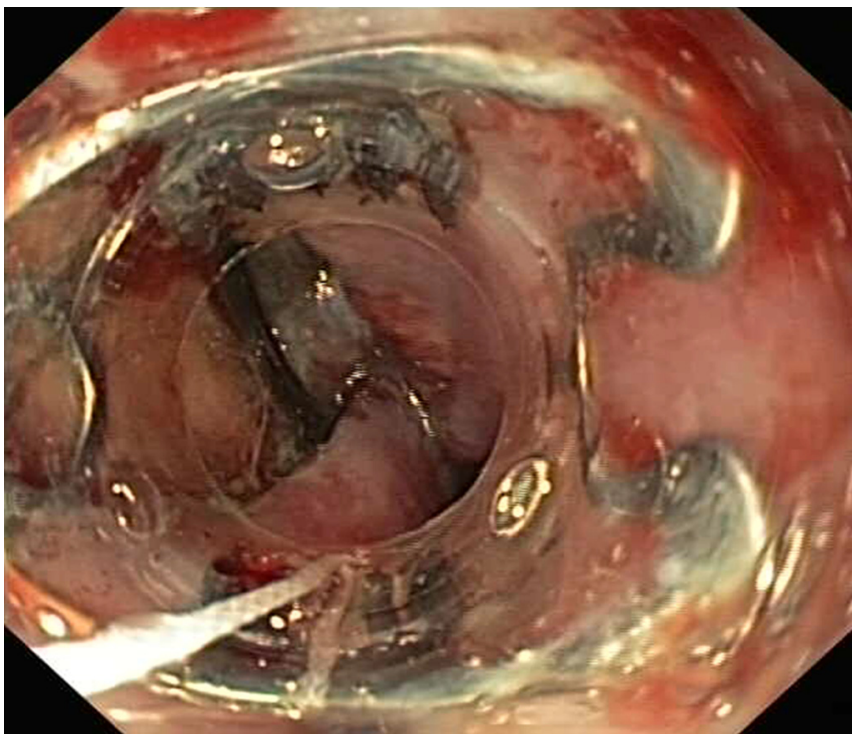

Figure 1. Endoscopic view of the over-the-endoscope clip and the large mural defect (left).

\section{WORLD CUP OF ENDOSCOPY WINNER}

A 51-year-old man was admitted with severe respiratory distress after spontaneous esophageal rupture after vomiting. The patient was considered too medically unstable to undergo open thoracotomy. EGD was performed (Fig. 1; Video 1, available online at www.giejournal.org), which revealed a $6-\mathrm{cm}$ long complete rupture of the distal esophageal wall. Two over-the-endoscope clips (OVESCO, Tübingen, Germany) were used to approximate the sides of the defect. A fully covered 8-cm long, 24-mm central/32-mm shoulder diameter colonic stent (Hanaro; M.I. Tech, Seoul, South Korea) was positioned over the defect and across the gastroesophageal junction and released under endoscopic guidance. Three days after the procedure, the patient was extubated, and 2 days later oral intake was

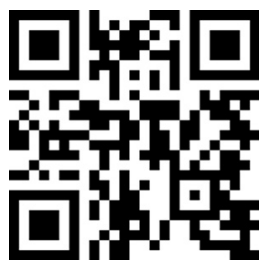

This video can be viewed directly from the GIE website or by using the QR code and your mobile device. Download a free $Q R$ code scanner by searching "QR Scanner" in your mobile device's app store. resumed. After 3 weeks, the patient was discharged in good clinical condition. The stent was removed 6 weeks after placement. By that time, the rupture had healed completely. Endoscopic control 6 months after the event showed complete restoration of the esophageal wall, without stricturing. The role of endoscopy in the treatment of Boerhaave syndrome is not clear. Stenting and endoscopic clipping have been reported to be successful in small case series, but larger series showed primary surgical therapy to be more successful. Careful consideration of all endoscopic and surgical options, in view of the patient's condition, remains mandatory.

Stijn J. B. Van Weyenberg, MD, Department of Gastroenterology and Hepatology, Leiden University Medical Center, Leiden, Fred J. Stam, RN, Department of Gastroenterology and Hepatology, VU University Medical Center, Amsterdam, Willem Marsman, MD, PhD, Department of Gastroenterology and Hepatology, Kennemer Gasthuis, Haarlem, the Netherlands

http://dx.doi.org/10.1016/j.gie.2014.03.048 